\title{
Enterotoxin A Synthesis in Staphylococcus aureus: Inhibition by Glycerol and Maltose
}

\author{
By J. L. SMITH, * M. M. BENCIVENGO AND C. A. KUNSCH \\ United States Department of Agriculture, 600 East Mermaid Lane, Philadelphia, \\ PA 19118, USA
}

(Received 21 March 1986; revised 16 July 1986)

\begin{abstract}
Studies indicated that prior growth of Staphylococcus aureus $196 \mathrm{E}$ on glycerol or maltose led to cells with repressed ability to produce staphylococcal enterotoxin A (SEA). A PTS ${ }^{-}$mutant (196E-MA) lacking the phosphoenolpyruvate phosphotransferase system (PTS), derived from strain 196E, showed considerably less repression of SEA synthesis when cells were grown in glycerol or maltose. Since SEA synthesis is not repressed in the PTS- mutant, repression of toxin synthesis by glycerol, maltose or glucose in $S$. aureus $196 \mathrm{E}$ appears to be related to the presence of a functional PTS irrespective of whether the carbohydrate requires the PTS for cell entry. With lactose as an inducer, glucose, glycerol, maltose or 2-deoxyglucose repressed the synthesis of $\beta$-galactosidase in $S$. aureus $196 \mathrm{E}$. It is postulated that these compounds repress enzyme synthesis by an inducer exclusion mechanism involving phosphorylated sugar intermediates. However, inducer exclusion probably does not explain the mechanism of repression of SEA synthesis by carbohydrates.
\end{abstract}

\section{INTRODUCTION}

Glucose represses the synthesis of staphylococcal enterotoxins A (SEA), B (SEB) and C (SEC) (Morse et al., 1969; Jarvis et al., 1975; Miller \& Fung, 1977; Iandolo \& Shafer, 1977; Smith et al., 1986). A greater repressive effect is observed if the cells are first grown in glucose-containing broth before being transferred to enterotoxin production medium (Morse et al., 1969; Jarvis et al., 1975; Smith et al., 1986). Jarvis et al. (1975) also demonstrated that glycerol repressed the synthesis of SEB but the effect of prior growth in glycerol on enterotoxin production was not determined.

Previously we showed that glucose, which is transported and phosphorylated in Staphylococcus aureus by the phosphoenolpyruvate phosphotransferase system (PTS), repressed SEA synthesis in S. aureus 196E (Smith et al., 1986). However, glucose did not repress SEA synthesis in a mutant which lacked a PTS, indicating that the PTS plays a role in the repression of SEA synthesis by glucose. Neither glycerol nor maltose is transported and phosphorylated via the PTS in S. aureus (Button et al., 1973; Richey \& Lin, 1973). It was of interest to determine the role of the PTS in inhibition of SEA synthesis by the non-PTS compounds, glycerol and maltose. Accordingly, the effect of glycerol and maltose on SEA synthesis in S. aureus $196 \mathrm{E}\left(\mathrm{PTS}^{+}\right)$and in $S$. aureus $196 \mathrm{E}-\mathrm{MA}\left(\mathrm{PTS}^{-}\right)$was investigated.

\section{METHODS}

Growth of cells. S. aureus $196 \mathrm{E}$ and 196E-MA (derived from strain 196E: Smith et al., 1986) were each inoculated into tryptic soy broth without glucose (TSB w/o glucose, Difco) both with and without the addition of sterile glycerol (final concn $2 \%, \mathrm{w} / \mathrm{v}$ ) or maltose (monohydrate, final concn $1 \%, \mathrm{w} / \mathrm{v}$ ). Culture flasks were incubated on a rotary shaker (200 r.p.m.) at $37^{\circ} \mathrm{C}$ for $16 \mathrm{~h}$.

Abbreviations: SEA, staphylococcal enterotoxin A; SEB, staphylococcal enterotoxin B; SEC, staphylococcal enterotoxin C; PTS, phosphoenolpyruvate phosphotransferase system; CAS, Casamino acids salts medium; TSB, tryptic soy broth. 
Production of SEA. Cells were harvested from the growth medium by centrifugation, washed twice with sterile $0 \cdot 1 \mathrm{M}$-potassium phosphate buffer ( $\mathrm{pH} 7 \cdot 2)$ and resuspended in sterile buffer. The SEA production medium was Casamino acids salts medium (CAS) (Smith et al., 1986). When either glycerol or maltose was added to CAS, it was sterilized by filtration and then added aseptically to the sterile medium.

Washed cells, suspended in buffer, were added to the CAS to give approximately $5 \times 10^{9} \mathrm{cells}^{-1}$. The flasks were then incubated at $37^{\circ} \mathrm{C}$ on a rotary shaker $(200$ r.p.m.) and samples were removed for pH and SEA determination after $24 \mathrm{~h}$.

Determination of SEA concentration. Bacteria were removed from the CAS by centrifuging in an Eppendorf centrifuge for $2 \mathrm{~min}$. To remove Protein A, normal rabbit serum was added to the supernatant to a final concentration of $5 \%(\mathrm{v} / \mathrm{v})$ serum. The serum/supernatant mixture was incubated at $5{ }^{\circ} \mathrm{C}$ for $1 \mathrm{~h}$ and then centrifuged (Fey et al., 1984). Dilutions of the Protein A-free supernatant were then used to determine the concentration of SEA by enzyme-linked immunosorbent assay (ELISA) (Smith \& Bencivengo, 1985). Goat and rabbit anti-SEA and purified SEA were a generous gift of Dr Anna Johnson, US Army Research Institute of Infectious Diseases, Frederick, Md., USA.

Determination of $\beta$-galactosidase activity. S. aureus $196 \mathrm{E}$ was inoculated into TSB w/o glucose containing $1 \%$ $(\mathrm{w} / \mathrm{v})$ added glucose and cultures were incubated at $37^{\circ} \mathrm{C}$ for $16 \mathrm{~h}$ on a rotary shaker $(200 \mathrm{r}$.p.m.). Bacteria were harvested by centrifugation, washed once with sterile distilled water, resuspended to $1 / 5$ of the culture volume in distilled water, and added to CAS containing lactose (inducer) plus either glucose, maltose or glycerol. Cells were added to give a final concentration of $1-5 \times 10^{9}$ bacteria ml-1 and incubated for $4 \mathrm{~h}$ at $37^{\circ} \mathrm{C}$ on a rotary shaker (200 r.p.m.). The bacteria were then harvested by centrifugation and washed twice with sterile distilled water. A sample of washed cells was dried $\left(100^{\circ} \mathrm{C}\right.$ overnight) to determine dry weight. A second sample was taken to determine $\beta$-galactosidase activity by the method of Dobrogosz (1981).

Determination of $\alpha$-glucosidase (EC 3.2.1.20) activity. S. aureus 196E and 196E-MA were grown in TSB w/o glucose plus glucose or maltose (each $1 \%, w / v)$ at $37^{\circ} \mathrm{C}$ for $16 \mathrm{~h}$ on a rotary shaker ( 200 r.p.m.). Cells were harvested and washed as described above and assayed for $\alpha$-glucosidase activity using the method of Halvorson (1966).

\section{RESULTS}

There was a fundamental difference in aerobic utilization of carbohydrates between the parent and mutant strains of $S$. aureus 196E. Under aerobic conditions, strain 196E produced acid from glucose, maltose or glycerol. The mutant, strain 196E-MA, produced acid from glucose but was less active on glycerol. No acid was produced from maltose, even when the maltose level was increased to $5 \%(\mathrm{w} / \mathrm{v})$. This agrees with earlier work (Smith et al., 1986) which indicated that the mutant was active on glycerol or glucose only, whereas the parent produced acid from a large number of carbohydrates. Additionally, the mutant strain was shown to lack an active PTS.

Production of SEA was repressed in glycerol-grown S. aureus 196E at glycerol concentrations that did not repress SEA synthesis in cells grown in the absence of glycerol (Table 1). In addition, as the glycerol level of CAS was increased, the decrease in pH was greater with glycerol-grown cells than with cells grown in medium lacking glycerol (Table 1). At similar $\mathrm{pH}$ values of the CAS, the decrease in toxin production was more pronounced with glycerol-grown cells than with cells grown in the absence of glycerol (Table 1).

Glycerol repression of SEA synthesis was not observed with the mutant, S. aureus 196E-MA, grown in the absence of glycerol (Table 1). The inhibition of SEA synthesis by glycerol-grown 196E-MA in CAS containing glycerol ranged from $9 \%$ (25 mM-glycerol) to $28 \%$ (200 mMglycerol). At high glycerol levels, the $\mathrm{pH}$ of CAS decreased to 5.0; however, enterotoxin production by the mutant strain did not decrease to the extent seen with the parent $S$. aureus $196 \mathrm{E}$ strain (Table 1). It would appear that $\mathrm{pH}$ is not a key factor in SEA repression.

Maltose also repressed SEA synthesis in $S$. aureus 196E (Table 2). There was greater repression with maltose-grown cells than with cells grown without maltose. Inhibition of SEA production by maltose-grown cells did not correlate with a decrease in $\mathrm{pH}$ since at similar $\mathrm{pH}$ values, there was less SEA produced by maltose-grown cells than by cells grown in the absence of maltose.

There was little or no repression of SEA synthesis by maltose with $S$. aureus 196E-MA grown in either the absence or presence of maltose (Table 2). Interestingly, the mutant produced acid in CAS containing maltose, as demonstrated by the decrease in $\mathrm{pH}$ (Table 2) even though the mutant did not lower the $\mathrm{pH}$ in TSB medium containing maltose. The mutant strain does 
Table 1. Effect of growth with or without glycerol on synthesis of SEA by S. aureus $196 E$ and $S$. aureus 196E-MA in CAS containing varying amounts of glycerol

The data shown represent one of four experiments, which showed identical trends.

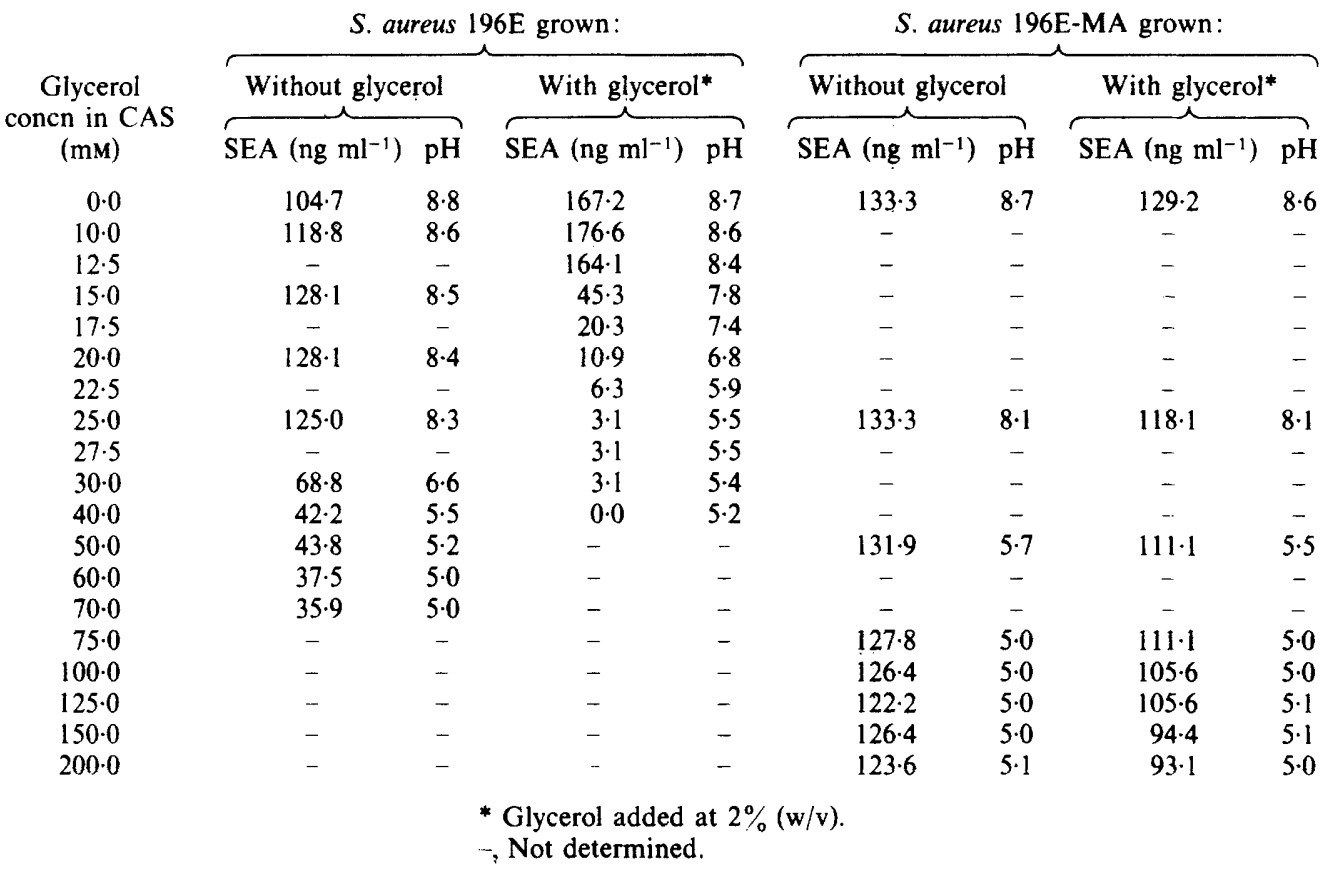

Table 2. Effect of growth with or without maltose on synthesis of SEA by S. aureus $196 E$ and $S$. aureus 196E-MA in CAS containing varying amounts of maltose

The data shown represent one of four experiments, which showed identical trends.

\begin{tabular}{|c|c|c|c|c|c|c|c|c|}
\hline \multirow{3}{*}{$\begin{array}{c}\text { Maltose } \\
\text { concn in CAS } \\
(\mathrm{mM})\end{array}$} & \multicolumn{4}{|c|}{ S. aureus $196 \mathrm{E}$ grown: } & \multicolumn{4}{|c|}{ S. aureus 196E-MA grown: } \\
\hline & \multicolumn{2}{|c|}{ Without maltose } & \multicolumn{2}{|c|}{ With maltose* } & \multicolumn{2}{|c|}{ Without maltose } & \multicolumn{2}{|l|}{ With maltose* } \\
\hline & SEA (ng ml-1) & $\mathrm{pH}$ & SEA (ng ml-1) & $\mathrm{pH}$ & SEA (ng ml $\left.{ }^{-1}\right)$ & $\mathrm{pH}$ & SEA (ng ml ${ }^{-1}$ ) & $\mathrm{pH}$ \\
\hline $0 \cdot 0$ & $101 \cdot 1$ & 8.8 & $122 \cdot 2$ & 8.5 & 115.6 & 8.6 & $109 \cdot 6$ & 8.6 \\
\hline $1 \cdot 0$ & 118.0 & 8.7 & 84.6 & $8 \cdot 3$ & - & - & - & - \\
\hline 1.5 & 147.0 & $8 \cdot 6$ & $80 \cdot 3$ & $8 \cdot 2$ & - & - & - & - \\
\hline $2 \cdot 0$ & 138.8 & $8 \cdot 4$ & $76 \cdot 3$ & 7.9 & - & - & - & - \\
\hline $2 \cdot 5$ & $142 \cdot 7$ & $8 \cdot 3$ & $68 \cdot 1$ & 7.5 & - & - & - & - \\
\hline $3 \cdot 0$ & $80 \cdot 3$ & $7 \cdot 0$ & $51 \cdot 2$ & 6.6 & - & - & - & - \\
\hline $3 \cdot 5$ & 84.6 & 6.6 & 34.7 & $6 \cdot 2$ & - & - & - & - \\
\hline $4 \cdot 0$ & $56 \cdot 2$ & $6 \cdot 3$ & 13.9 & $5 \cdot 5$ & - & - & - & - \\
\hline $4 \cdot 5$ & $19 \cdot 2$ & 5.8 & $10 \cdot 9$ & $5 \cdot 0$ & - & - & - & - \\
\hline $50 \cdot 0$ & - & - & - & - & 113.7 & 7.8 & 116.4 & $8 \cdot 1$ \\
\hline $100 \cdot 0$ & - & - & - & - & 127.4 & 5.9 & $115 \cdot 1$ & 7.5 \\
\hline $150 \cdot 0$ & - & - & - & - & $122 \cdot 0$ & $5 \cdot 6$ & $119 \cdot 2$ & 5.9 \\
\hline $200 \cdot 0$ & - & - & - & - & 112.0 & $5 \cdot 5$ & $109 \cdot 6$ & 5.7 \\
\hline & & & $\begin{array}{l}\text { Maltose add } \\
\text { Not determ }\end{array}$ & & & & & \\
\hline
\end{tabular}

contain $\alpha$-glucosidase and thus can split maltose. Unlike the parent strain 196E, synthesis of $\alpha$-glucosidase by the mutant was not repressed by glucose nor induced by maltose (data not shown). $\alpha$-Glucosidase activity was not detected in the culture supernatant fluids of either strain. 
Table 3. Effect of glucose, maltose, glycerol and a glucose analogue on synthesis of $\beta$-galactosidase in S. aureus $196 \mathrm{E}$

Data shown represent one of three experiments, which showed identical trends.

$\begin{array}{lcc}\quad \text { Addition to CAS } & \mathrm{pH}^{*} & \beta \text {-Galactosidase } \dagger \\ \text { None } & 7 \cdot 4 & 9 \cdot 8 \\ \text { Lactose }(5 \mathrm{mM}) & 5 \cdot 4 & 270 \cdot 9 \\ \text { Lactose }(5 \mathrm{mM})+\text { glucose }(5 \mathrm{mM}) & 5 \cdot 4 & 146 \cdot 0 \\ \text { Lactose }(5 \mathrm{mM})+\text { glucose }(10 \mathrm{mM}) & 5 \cdot 2 & 52 \cdot 5 \\ \text { Lactose }(5 \mathrm{mM})+\text { maltose }(5 \mathrm{mM}) & 5 \cdot 2 & 58 \cdot 0 \\ \text { Lactose }(5 \mathrm{mM})+\text { maltose }(10 \mathrm{mM}) & 4 \cdot 7 & 40 \cdot 2 \\ \text { Lactose }(5 \mathrm{mM})+\text { glycerol }(10 \mathrm{mM}) & 5 \cdot 5 & 146 \cdot 4 \\ \text { Lactose }(5 \mathrm{mM})+\text { glycerol }(20 \mathrm{mM}) & 5 \cdot 4 & 124 \cdot 5 \\ \text { Lactose }(5 \mathrm{mM})+\text { 2-deoxyglucose }(5 \mathrm{mM}) & 7 \cdot 4 & 28 \cdot 8 \\ & & \\ \text { at } 4 \text { h incubation. } & & \\ \text { dase activity is expressed as } \mu \mathrm{g} o \text {-nitrophenol }(30 \mathrm{~min})^{-1}(10 \mathrm{mg} \text { dry wt cells })^{-1} \text { with } o \text {-nitrophenyl } \\ \text { as the substrate. }\end{array}$

Glucose, glycerol and maltose inhibited lactose induction of $\beta$-galactosidase in $S$. aureus $196 \mathrm{E}$ (Table 3). Glycerol, however, was not as effective as the two sugars in repressing the synthesis of the enzyme. In addition, the glucose analogue 2-deoxyglucose inhibited the synthesis of staphylococcal $\beta$-galactosidase. $\beta$-Galactosidase activity could not be demonstrated in $S$. aureus 196E-MA.

\section{DISCUSSION}

Previously we demonstrated that SEA synthesis in $S$. aureus $196 \mathrm{E}$ was repressed when the cells were first grown in medium containing glucose. The repression became more severe as the concentration of glucose in CAS increased (Smith et al., 1986). Our present results with glycerol and maltose were similar to those obtained with glucose: SEA synthesis was repressed more severely in $S$. aureus subjected to prior growth in glycerol or maltose. Maltose-grown $S$. aureus 196E-MA did not show repression of SEA synthesis; however, there was a small repressive effect on SEA synthesis when the mutant strain was grown in glycerol and suspended in CAS containing high levels of glycerol. Metabolism of glycerol or maltose by the mutant strain decreased the $\mathrm{pH}$ of CAS to levels similar to that produced by the parent $196 \mathrm{E}$ strain; yet the decreased $\mathrm{pH}$ did not lead to inhibition of enterotoxin synthesis in the mutant strain. That strain 196E-MA decreased the $\mathrm{pH}$ value without a concomitant inhibition of SEA synthesis indicates that repression of SEA synthesis in S. aureus $196 \mathrm{E}$ by glycerol or maltose is not due to decrease in $\mathrm{pH}$.

A large number of carbohydrates and related compounds are transported and phosphorylated in S. aureus via the PTS (Friedman \& Hays, 1977). These compounds include lactose, sucrose, galactose, glucose, mannose, fructose, mannitol and various analogues such as 2-deoxyglucose, $\alpha$-methylglucose and $o$-nitrophenyl $\beta$-D-galactoside. In $S$. aureus, only lactose and mannitol appear to have inducible enzymes for PTS activity, and the carbohydrate-specific components of the PTS are induced by growth of $S$. aureus in the presence of lactose or mannitol (Nakazawa et al., 1971; Friedman \& Hays, 1977). In S. aureus, glycerol and maltose do not depend on PTS for transport and phosphorylation (Richey \& Lin, 1973; Button et al., 1973); they probably enter the cells by a facilitated diffusion mechanism.

Glycerol and maltose repressed the synthesis of alpha toxin in S. aureus (Duncan \& Cho, 1972) while glycerol repressed $\beta$-galactosidase and SEB synthesis (McClatchy \& Rosenblum, 1963; Jarvis et al., 1975). We found that not only did glycerol and maltose repress SEA synthesis in $S$. aureus $196 \mathrm{E}$ but they also inhibited $\beta$-galactosidase synthesis. However, glycerol was not as effective as maltose or glucose in repressing $\beta$-galactosidase production.

The mechanism by which glucose, maltose or glycerol inhibit the production of $\beta$ galactosidase or SEA is not clear. A mechanism for their repression of $\beta$-galactosidase synthesis could include interference by intracellular sugar phosphates of uptake of various carbohydrates 
by an inducer exclusion mechanism (Saier \& Simoni, 1976; Saier, 1985). When glucose-grown $S$. aureus $196 \mathrm{E}$ was presented with lactose and glucose simultaneously, little or no formation of $\beta$ galactosidase resulted. Glucose would enter the cell via the constitutive glucose PTS (Friedman \& Hays, 1977) and the resultant glucose 6-phosphate (G6P) or some other phosphorylated intermediate derived from glucose could prevent the formation of the induced lactose-specific PTS enzymes. As a result, lactose would not gain entry to the cell and would be unavailable for enzyme induction.

Maltose enters the staphylococcal cell via facilitated diffusion (Button et al., 1973). Glucose formed by the action of $\alpha$-glucosidase would be phosphorylated to G6P (or some other phosphorylated intermediate), which would prevent the induction of the lactose-specific PTS enzymes. Glycerol is also transported into the cell by a facilitated diffusion mechanism (Richey \& Lin, 1973) so it is possible that a phosphorylated glycerol derivative represses the uptake of lactose.

The repression of $\beta$-galactosidase synthesis by 2-deoxyglucose (Table 3) supports the postulated inhibition of induced enzyme synthesis by G6P. The glucose analogue is phosphorylated to the 6-phosphate compound via the PTS in $S$. aureus, but is not further metabolized (Friedman \& Hays, 1977; Iandolo \& Shafer, 1977). The non-metabolizable 2deoxyglucose 6-phosphate derivative may prevent the entry of lactose into the cell. While the mechanism of inducer exclusion by sugar-phosphate intermediates may be an explanation for repression of lactose-induced $\beta$-galactosidase synthesis in $S$. aureus $196 \mathrm{E}$, it does not appear to be a viable mechanism for explaining SEA repression by glycerol, maltose or glucose. However, phosphorylated sugar intermediates may inhibit SEA synthesis by some mechanism other than inducer exclusion.

The data presented here indicate that even though glycerol and maltose are not transported via the PTS, it is necessary for the cells to have an effective PTS in order to demonstrate repression of SEA synthesis since these compounds do not repress SEA synthesis in the PTSmutant. Further, our results indicate that repression is not due to decrease in $\mathrm{pH}$ effected by metabolism of glycerol or maltose.

\section{REFERENCES}

Button, D. K., Egan, J. B., Hengstenberg, W. \& Morse, M. L. (1973). Carbohydrate transport in Staphylococcus aureus. IV. Maltose accumulation and metabolism. Biochemical and Biophysical Research Communications 52, 850-855.

DoBrogosz, W. J. (1981). Enzymatic activity. In Manual of Methods for General Bacteriology, pp. 365392. Edited by P. Gerhardt. Washington, DC: American Society for Microbiology.

Duncan, J. L. \& Chо, G. J. (1972). Production of staphylococcal alpha toxin. II. Glucose repression of toxin formation. Infection and Immunity 6, 689-694.

Fey, H., Pfister, H. \& Ruegg, O. (1984). Comparative evaluation of different enzyme-linked immunosorbent assay systems for the detection of staphylococcal enterotoxin A, B, C, and D. Journal of Clinical Microbiology' 19, 34 38.

Friedman, S. A. \& HaYs, J. B. (1977). Initial characterization of hexose and hexitol phosphoenolpyruvate-dependent phosphotransferases of Staphylococcus aureus. Journal of Bacteriology 130, 991-999.

HaLvorson, H. (1966). $\alpha$-Glucosidase from yeast. Methods in Enzymology 8, 559-562.

IANDOLO, J. J. \& SHAFER, W. M. (1977). Regulation of staphylococcal enterotoxin B. Infection and Immunity 16, 610-616.

JaRvis, A. W., Lawrence, R. C. \& Pritchard, G. G. (1975). Glucose repression of enterotoxin A, B and C and other extracellular proteins in staphylococci in batch and continuous culture. Journal of General Microbiology 86, 75-87.

McClatchy, J. K. \& Rosenblum, E. E. (1963). Induction of lactose utilization in Staphylococcus aureus. Journal of Bacteriology 86, 1211-1215.

MILLER, R. D. \& FUNG, D. Y. C. (1977). The excretion of enterotoxin B from nongrowing cells of Staphylococcus aureus. Canadian Journal of Microbiology 23, 369-377.

Morse, S. A., MAH, R. A. \& Dobrogosz, W. J. (1969). Regulation of staphylococcal enterotoxin B. Journal of Bacteriology 98, 4-9.

Nakazawa, T., Simoni, R. D., Hays, J. B. \& Roseman, S. (1971). Phosphorylation of a sugar-specific protein component of the lactose transport system in Staphylococcus aureus. Biochemical and Biophysical Research Communications 42, 836-843.

RICHEY, D. P. \& LIN, E. C. C. (1973). Phosphorylation of glycerol in Staphylococcus aureus. Journal of Bacteriology 114, 880-881.

SAIER, M. H., JR (1985). Mechanism and Regulation of Carbohydrate Transport in Bacteria. New York: Academic Press.

SAIER, M. H., JR \& Simoni, R. D. (1976). Regulation of carbohydrate uptake in Gram-positive bacteria. Journal of Biological Chemistry 251, 893-894.

Smith, J. L. \& Bencivengo, M M. (1985). A review of 
methods for detection of staphylococcal enterotoxins and evaluation of an enzyme-linked immunosorbent assay applied to foods. Journal of Food Safety 7,83 . 100 .
Smith, J. L.. Bencivengo, M. M., Buchanan, R. L. \& KUNSCH, C. A. (1986). Enterotoxin A production in Staphylococcus aureus: inhibition by glucose. Archives of Microhiology 144, 131 136. 